\title{
Health-related quality of life in pediatric and adolescent patients with transfusion- dependent ß-thalassemia in upper Egypt (single center study)
}

\author{
Gehan L Abdel Hakeem ${ }^{1 *}$, Suzan O Mousa ${ }^{1}$, Asmaa N Moustafa ${ }^{1}$, Mohamed H Mahgoob \\ and Ebtesam E Hassan ${ }^{2}$
}

\begin{abstract}
Background: Thalassemia is a major health problem that disturbs the lifestyle of the affected patient. The aim of this work is to detect the impact of thalassemia on the quality of life regarding physical, social, emotional, psychological scored assessment.

Methods: A case-control survey was conducted in Minia University children's hospital on 64 patients recruiting pediatric hematology outpatient clinic from July 2014 to February 2017. PedsQL ${ }^{\text {TM }} 4.0$ Generic Core Scale (Arabic version) was used to assess HRQOL in 64 thalassemia patients between 8 and 18 years of ages. Other related clinical data of the involved patients were collected from the pediatric hematology records.

Results: Mean physical, emotional, social, school performance, psychological and total scores $(-36.9 \pm 20.9,49.4 \pm 17,47$. $2 \pm 21.3,38.5 \pm 15.5,45.3 \pm 13.8,47.9 \pm 38.8$ respectively) were significantly decreased compared with control ( $p=0.001$ for all). The younger age group had better scores regarding social, emotional, psychological and total scores compared to older ones ( $p=0.01,0.03,0.01$ and 0.009 respectively). Older age of starting transfusion was statistically significant protecting factor from poor physical $\mathrm{QOL}$ in thalassemia patients $(\mathrm{OR}=0.96, p=0.03)$. The presence of hepatomegaly was a statistically significant predictor for poor physical $\mathrm{QOL}(\mathrm{OR}=8.5, p=0.02)$. Household income was the statistically significant predictor for poor emotional $\mathrm{QOL}(\mathrm{OR}=5.03, p=0.04)$. High serum ferritin was the statistically significant predictor for poor social $\mathrm{QOL}(\mathrm{OR}=1.1, \mathrm{Cl} 95 \%=, p=0.04)$. Regarding poor psychological $\mathrm{QOL}(\mathrm{OR}=0.94, p=0.01)$ and total $Q O L(O R=0.94, p=0.01)$ scores, older age of starting transfusion was the statistically significant protecting factor.

Conclusion: Scheduled programs giving psychosocial help and a network connecting between the patients, school officials, thalassemia caregivers and the physician is required especially in developing countries where the health services are not integrated with social organizations. Special school services for thalassemia patients are required to deal with the repeated absence and anemia induced low mental performance of thalassemia children.
\end{abstract}

\section{Background}

Beta-thalassemia is one of the most common autosomal recessive disorders worldwide with high prevalence in the Mediterranean, Middle-East and Central Asia [1]. Betathalassemia is caused by the reduced or absent beta globin chain synthesis of hemoglobin $(\mathrm{Hb})$ tetramer, which is

\footnotetext{
* Correspondence: gehanlotfy72@yahoo.com

${ }^{1}$ Pediatric Department, Faculty of Medicine, Minia University, El Minya 61511, Egypt

Full list of author information is available at the end of the article
}

made up of two alpha globin and two beta globin chains $\left(\right.$ alpha $_{2}$ beta $\left._{2}\right)$. The clinical severity of beta-thalassemia is related to the imbalance between the alpha globin and non-alpha globin chains [2-4].

Individuals with Beta-thalassemia major usually present with failure to thrive and progressive pallor requiring regular blood transfusions to survive, abdominal enlargement, caused by splenomegaly and the risk of developing iron overload related complications. Complications of iron overload include growth retardation and failure of sexual

(c) The Author(s). 2018 Open Access This article is distributed under the terms of the Creative Commons Attribution 4.0 International License (http://creativecommons.org/licenses/by/4.0/) which permits unrestricted use, distribution, and reproduction in any medium, provided you give appropriate credit to the original author(s) and the source, provide a link to the Creative Commons license, and indicate if changes were made. The Creative Commons Public Domain Dedication waiver (http://creativecommons.org/publicdomain/zero/1.0/) applies to the data made available in this article, unless otherwise stated. 
maturation. Late complications are cardiac (dilated myocardiopathy and pericarditis), hepatic (chronic hepatitis, fibrosis, and cirrhosis), endocrinal (resulting in diabetes mellitus and parathyroid, thyroid, pituitary, and, less commonly, adrenal glands insufficiencies) and hypersplenism [5-7].

In Egypt, $\beta$-Thalassemia is the most frequent hemoglobinopathy. The carrier rate of this disease varies between $5.3-9 \%$ and the gene frequency is $0.03 \%$. It was estimated that 1000/ 1.5 million per year live birth born with thalassemia disease [8]. Children with transfusiondependent thalassemia typically should undergo blood transfusions once or twice a month depending on the severity of the illness. This may force them to spend the entire transfusion day at the hospital with subsequent disruption in education and social activities. Iron overload with the undesirable bronzed color may compromise their body image. With regular deferoxamine Injection therapy for iron chelation, they become increasingly dependent upon others [9]. Adding to these, the complications of iron overload which may become evident when chelation is not feasible or due to lack of patient compliance.

Overall patient's life, such as education, free-time, physical activities, skills, capabilities, and family adjustment is affected. The effects of which often result in psychological, emotional and social compromise [10].

Health-Related Quality of Life (HRQoL) measurement is a multidimensional concept that focuses on the impact of the disease and its treatment on the wellbeing of an individual. The measures are seen as ways of capturing patients' perspectives of their disease and treatment, their perceived need for health care and their preferences for treatment and disease outcomes [11].

Varni et al., 2003 created the multidimensional PedsQL 4.0 questionnaire to measure the essential core domains for pediatric HRQoL: Physical functioning, Emotional functioning, and social functioning, as delineated by the World Health Organization (WHO), as well as School functioning [12, 13].

Some recent searches studied the HRQoL of Bthalassemia children and adults and their parents. They found that treatment and cultural differences did not have a major effect on the Quality of life in Cypriot thalassemia patients [14]. Another study on children compared the quality of life in patients with thalassemia intermedia to thalassemia major and discovered that transfusion-independent thalassemia patients also suffer impairments in different quality of life aspects [15]. They concluded that all patients with thalassemia should undergo QOL assessment so that interventions focused on the affected domain can be implemented.

In this study, we aimed to evaluate the quality of life in children and adolescents with thalassemia in El Minya governorate, at Upper Egypt, and to investigate which factors can lead to the establishment of good supportive clinical programs that will improve quality of life in these patients especially that stem cell transplantation is not an option for most of them.

\section{Methods}

This case-control study was done at the pediatric hematology unit in Minia University children's hospital from July 2014 to February 2017. The enrolled patients were known recorded thalassemia patients that had regular visits to pediatric hematology unit either for clinical and laboratory follow-up or regularly scheduled blood transfusion. The patients were asked to answer the questionnaire during their regular planned visits to the hematology clinic. One hundred eligible beta-thalassemia patients were invited to participate in this study. Only 64 of them agreed to participate.

\section{Eligibility}

Beta thalassemia children fulfilling the following criteria during the study period were included: having an age range between 8 and 18 years, receiving a blood transfusion on a monthly or near-monthly basis.

\section{Exclusion criteria}

We excluded from the study: (1) Beta-thalassemia patients suffering from any acute illness that made it difficult to answer the questionnaire such as acute heart failure, acute, thalassemia patients with any associated chronic disease not related to thalassemia or its complications.

\section{Control group}

Sixty-four healthy age and sex matched students selected during school days were invited to participate in this study as a control group. They were apparently clinically healthy confirmed by a complete blood count.

For all enrolled patients, fully recorded data about their disease history including disease onset, the age of first blood transfusion, the amount of blood transfusion calculated per weight yearly, type, doses and duration of chelation therapy. Initial investigations including complete blood count $(\mathrm{CBC})$, serial serum ferritin measures and hepatitis $B$ and $C$ serology were also recorded. All patients were treated according to the international thalassemia federation guidelines.The cut-off value for serum ferritin to start iron chelation therapy was $>1000 \mathrm{ng} / \mathrm{ml}$ [16].

Full physical examination to the enrolled patients including anthropometric measures (weight, height, and head circumference) plotted to the child disease center (CDC) growth charts to be expressed as percentile numbers [17] in addition to complete chest, heart, and abdominal examinations. 
The study was explained in detail to the participant children and written consents were taken from their parents or legal guardians after assuring confidentiality of the data. The study was conducted according to the principles of Helsinki and the protocol of the study was approved by the Institutional Review Board and Medical Ethics Committee of Minia University hospital.

\section{Research instruments}

HRQoL was assessed with the PedsQoL 4.0 Generic Core Scales. This instrument has 23-items that are designed to measure the core dimensions of health as delineated by WHO. The PedsQoL 4.0 encompasses the essential core domains for pediatric HRQoL measurement: 1) Physical functioning (8 items), 2) Emotional functioning (5items), 3) Social functioning (5 items) and 4) School functioning (5 items). It consists of developmentally appropriate forms for ages $2-4,5-7$, and 8-12 and 13-18 years. The reliability, validity, responsiveness, and practicality of the PedsQoL Generic Core Scales have been assessed in both physically healthy pediatric populations and in pediatric acute and chronic health conditions. The internal consistency reliability of the PedsQoL 4.0 Generic Core Scale approached 0.90 for self-report [11, 12, 18]. The scores for each dimension were in alignment with the recommended approach and were calculated as follows: the mean score is represented by the sum of the items over the number of items answered; missing values (which were minimal in our study) were replaced by the mean score of the remaining items, Raw scores are transformed into standardized scores on a scale from 0 to 100 with higher scores representing higher functioning levels. The validity of the PedsQoL Generic Core Scales has been demonstrated through known group comparisons and correlations with other measures of disease burden.

User agreement was signed with MAPI Research Institute, Lyon, France prior to using the questionnaires. PedsQL 4.0 Generic Core Scales has also been translated into many languages and we used Arabic for Egypt version provided by MAPI Research Institute [18].

\section{Data analysis}

Data were computed and analyzed by and SPSS (Statistical Package for the Social Sciences) program version 19.0. General characteristics of the patients were presented in terms of percentage, mean, and standard deviation and median for data not normally distributed. For QoL, both total HRQoL score and physical, emotional, social, school achievement and psychological scores were presented in terms of mean and standard deviation. Pearson's correlation, chi-square, ANOVA, and t-test were used to examine the relationship between HRQoL and each demographic/clinical data. Non-parametric tests were used if data were not normally distributed. Factors influencing the quality of life of children with thalassemia were later examined by multiple regression analysis.

\section{Results}

Sixty-four known thalassemia patients were included. Forty-three $(67.2 \%)$ of them were males while $21(32.8 \%)$ were females. Their age range was 8-18 years with a mean of $12.1 \pm 3.2$. Another 64 apparently healthy age and sex matched children were enrolled as controls. Their age range was 8-18 years with a mean of $11.1 \pm 2.8$. Significant differences between beta thalassemia patients and the control group regarding mean weight centile (25.9 \pm 18.5 for thalassemia patients and $63+19.3$ for controls) and height centile $(5.7 \pm 10.5$ for thalassemia patients and $56.1 \pm 22.8$ for controls) ( $p$ values $=0.001$ for both) $($ Table 1$)$. Mean physical score was $36.9 \pm 20.9$ for patients and $78.4 \pm$ 5.5 for controls and was significantly different $(p=0.001)$. For the emotional score, it was $49.4 \pm 17$ for patients and was $74.3 \pm 5.5$ for controls with a significant difference $(p=0.001)$. Regarding mean social score, it was $47.2 \pm 21.3$ in patients while was $77 \pm 13.9$ in the control group with a significant difference $(p=0.001)$. Mean school achievement score was $38.5 \pm 15.5$ in patients while was $78.5 \pm 6.4$ in the control group with a significant difference $(p=0.001)$. The mean psychological score was $45.3 \pm 13.8$ in patients while was 76.6 \pm 3.2 in the control group with a significant difference $(\mathrm{p}=0.001)$. The total QoL score mean was $47.9 \pm 38.8$ in thalassemia patients while was $79.7 \pm 5.9$ in control group with a significant difference $(p=0.001)$ (Fig. 1). There were significant differences between children (8-12 years) and teens (13-18 years) regarding emotional, social and psychological scores $(p=0.03,0.013$ and 0.04 respectively). Comparing the physical and total QoL scores to the demographic and laboratory data, no significant differences were found (Table 2).

No significant correlations were found between different QoL scores and either the age of starting transfusion or the age of starting chelation ( $p=0.1$ for both).

On the age groups, the children group had significantly higher scores regarding the emotional, social, psychological performance as well as the total HRQoL score $(p=0.027,0.01,0.01$ and 0.009 respectively). Also, the children group had higher but statistically insignificant physical and school performance scores ( $p=0.9,0.13$ respectively) (Table 3 ).

Regression analysis showed that older age of starting transfusion in thalassemia patients was the most powerful protecting factor from poor physical QoL $(\mathrm{OR}=0.96$, $p=0.03)$, poor psychological QoL $(\mathrm{OR}=0.94, p=0.01)$ and low total QoL score $(\mathrm{OR}=0.94, p=0.01)$. While 
Table 1 Demographic, clinical and laboratory data of studied children

\begin{tabular}{|c|c|c|c|c|}
\hline \multirow[t]{2}{*}{ Parameters } & & \multirow{2}{*}{$\begin{array}{l}\text { Patients } \\
N=64\end{array}$} & \multirow{2}{*}{$\begin{array}{l}\text { Controls } \\
N=64\end{array}$} & \multirow[t]{2}{*}{$p$-value } \\
\hline & & & & \\
\hline \multirow[t]{3}{*}{ Age } & Range & $8-18$ & $8-18$ & 0.16 \\
\hline & Mean \pm SD & $12.1 \pm 3.2$ & $11.1 \pm 2.8$ & \\
\hline & median & 10 & 12 & \\
\hline \multirow[t]{2}{*}{ Sex } & Male & $43(67.2 \%)$ & $53(82.8 \%)$ & 0.15 \\
\hline & female & $21(32.8 \%)$ & $11(17.2 \%)$ & \\
\hline \multirow[t]{3}{*}{ Weight centile } & Range & $5-90$ & $25-95$ & $0.001^{*}$ \\
\hline & Mean \pm SD & $25.9 \pm 18.5$ & $63 \pm 19.3$ & \\
\hline & Median & 30 & 55 & \\
\hline \multirow[t]{3}{*}{ Height centile } & Range & $5-90$ & $10-95$ & $0.001^{*}$ \\
\hline & Mean $\pm S D$ & $15.7 \pm 10.5$ & $56.1 \pm 22.8$ & \\
\hline & Median & 20 & 59 & \\
\hline \multirow[t]{3}{*}{ Head circumference centile } & Range & $18-90$ & $15-95$ & 0.22 \\
\hline & Mean $\pm S D$ & $68.2 \pm 19$ & $63.2 \pm 16.1$ & \\
\hline & Median & 75 & 79 & \\
\hline \multirow[t]{3}{*}{ Educational status: } & -Uneducated & $20(31.2 \%)$ & $0(0 \%)$ & $0.005^{*}$ \\
\hline & -Primary school & $31(48.4 \%)$ & $50(78.1 \%)$ & \\
\hline & -Secondary school & $13(20.4 \%)$ & $14(21.9 \%)$ & \\
\hline \multirow[t]{3}{*}{ Household income } & $<500$ EGP & $15(23.4 \%)$ & $20(30 \%)$ & $0.02^{*}$ \\
\hline & $500-1000$ & $34(53.2 \%)$ & $24(40 \%)$ & \\
\hline & $>1000$ & $15(23.4 \%)$ & $20(30 \%)$ & \\
\hline \multirow[t]{3}{*}{ Age of start transfusion (month) } & Range & $6-72$ & - & \\
\hline & Mean $\pm S D$ & $15.8 \pm 11.8$ & & \\
\hline & Median & 10.5 & & \\
\hline \multirow[t]{3}{*}{ Age of start chelation } & Range & $2-12$ & & \\
\hline & Mean \pm SD & $4.1 \pm 2.6$ & & \\
\hline & Median & 4 & & \\
\hline \multirow[t]{4}{*}{ Type of chelation used } & No chelation & 7 (10.9\%) & & \\
\hline & Deferoxamine & $20(31.3 \%)$ & & \\
\hline & Deferoperone & $13(20.3 \%)$ & & \\
\hline & Desferosirax & $24(37.5 \%)$ & & \\
\hline \multirow[t]{2}{*}{ Liver enlargement } & Hepatomegaly & 49 (76.6\%) & & \\
\hline & No hepatomegaly & $15(23.4 \%)$ & & \\
\hline \multirow[t]{2}{*}{ Splenectomized } & No & $34(53.1 \%)$ & & \\
\hline & Yes & $30(46.9 \%)$ & & \\
\hline \multirow[t]{2}{*}{ Hepatitis C infection } & Positive & $22(34.4 \%)$ & & \\
\hline & Negative & $42(65.6 \%)$ & & \\
\hline \multirow[t]{2}{*}{ Hepatitis B infection } & Positive & $0(0 \%)$ & & \\
\hline & Negative & $64(100 \%)$ & & \\
\hline Serum ferritin (ng/ml) & Mean \pm SD & $975 \pm 22.1$ & $43 \pm 3.7$ & $0.001 *$ \\
\hline
\end{tabular}

* $=$ Significant $(p<0.05)$

hepatomegaly was the most predicting factor for poor physical QoL $(\mathrm{OR}=8.5, p=0.02)$. Household income was the most predicting factor for poor emotional QoL
$(\mathrm{OR}=5.03, p=0.04)$. High serum ferritin is the most predicting factor for poor social QoL (OR $=1.1, p=0.04)$ (Table 4). 


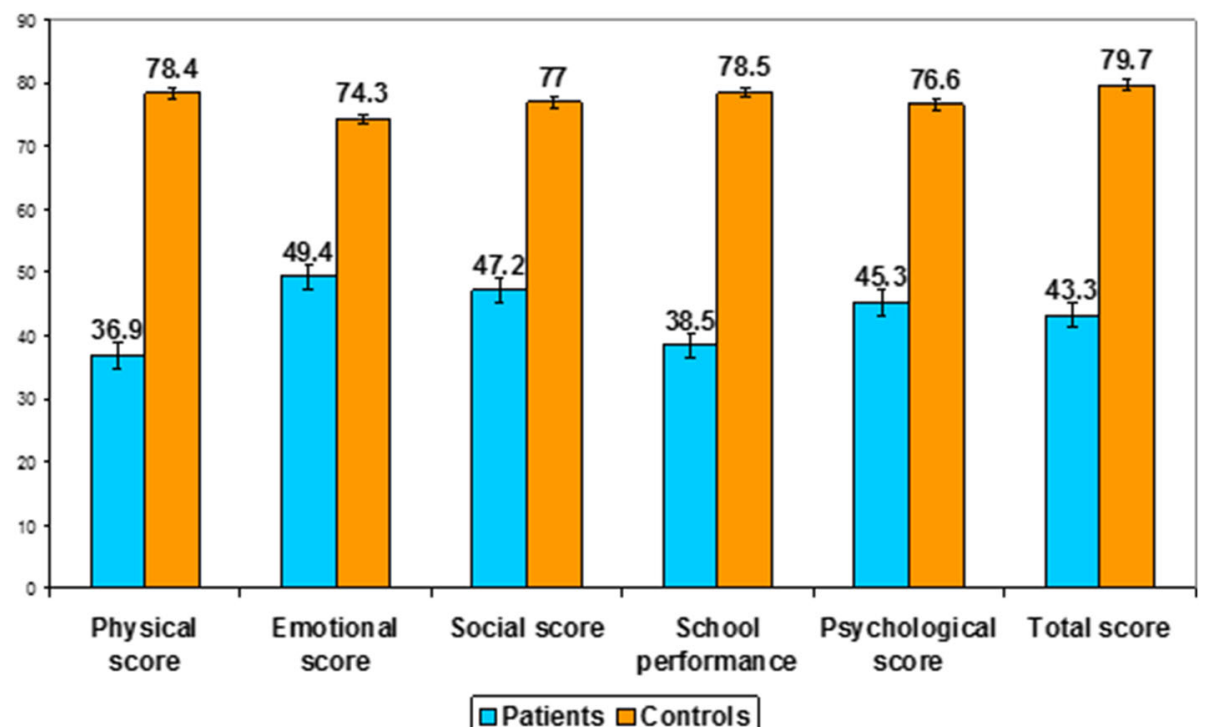

Fig. 1 QOL scores in thalassemia children and control: $(n=64$ cases and 64 control); $p<0.001$ in all scores

\section{Discussion}

In the present study, assessing the QoL in beta thalassemia major (BTM) children in Minia governorate showed the impact of BTM on the patients' performance in different aspects of life. The enrolled patients had lower growth parameters, as well as lower physical, social, emotional, school functioning, and total QoL scores compared with their matched healthy peers. Lower growth parameters and QoL scores in BTM patients have recognized observations in previous studies $[19,20]$ that can be attributed to the chronic anemic state and/or the consequences of iron overload.

Physical performance was the most severely affected parameter in thalassemia patients.

Chronic anemia status with consequent easy fatigability is the most important cause of physical performance deterioration in thalassemia patients. This is aggravated by repeated unavailability of the matched blood and needing to travel long distances from the far rural areas to the central hospital transfusion center. All these factors may lead to irregular blood transfusion and thus aggravate the anemic impact on physical activity, which explains low physical score in thalassemic patients [21, 22].

The low emotional and psychological scores could also be cofactors in the deterioration of physical activities [23-26]. The younger age of starting transfusion was associated with poor HRQoL. A longer period of exposure to the circumstances of repeated transfusion has a great burden on the fitness and physical performance of the thalassemia patients. Moreover, the longer period of exposure to iron metabolites specifically in the liver and other different tissues is an important factor affecting physical performance.

The enrolled BTM patients had low social performance compared to healthy children. The majority of young thalassemia patients can share playing with other kids or being a member of a play team. The absence of evident disease complications at a young age results in decreased feeling of stigmatization. As the patient grows, he recognizes the nature of his disease, he experiences repeated blood transfusion visits and school absence, and the characteristic morphological changes of thalassemia become more evident, all these factors may result in poor self-esteem and expressed negative thoughts about their lives and felt sadness, anger, and hurt toward their chronic illness. Social withdrawal and low social performance will be the result [27].

School functioning subscale scored the lowest in thalassemia patients regardless of the age. Frequent school absence for hospital visits and lack of both mental and physical energies when achieving academic educational activities [20, 28-32].

Chronic anemia, poverty and parents' illiteracy in most thalassemia patients put schooling and education in the last priority for these patients.

The Psychosocial health summary scores of our patients were lower than healthy controls. Thalassemia patients may suffer from higher levels of depression and anxiety which experience a significant decrease in their psychological wellbeing [33, 34]. This finding seems to support previous studies on psychosocial aspects of thalassemia that more psychosocial support should be given to thalassemia patients $[35,36]$. 





Table 3 Comparison between different scores regarding the age groups

\begin{tabular}{llll}
\hline Parameter & $\begin{array}{l}\text { Age 8-12 } \\
N=39\end{array}$ & $\begin{array}{l}\text { Age 13-18 } \\
N=25\end{array}$ & $P$ value \\
\hline Mean Physical score & $40.3 \pm 2.6$ & $31.7 \pm 11.7$ & 0.09 \\
Mean emotional score & $53.1 \pm 1.8$ & $43.6 \pm 6.1$ & $0.027^{*}$ \\
Mean Social score & $53.4 \pm 2.8$ & $39 \pm 1.2$ & $0.01^{*}$ \\
Mean School performance & $40.9 \pm 1.6$ & $34.9 \pm 3.9$ & 0.13 \\
Mean Psychological score & $47.9 \pm 1.5$ & $41.1 \pm 4.9$ & $0.01^{*}$ \\
Mean Total score & $46.8 \pm 5.9$ & $37.8 \pm 8.7$ & $0.009^{*}$ \\
\hline
\end{tabular}

${ }^{*}=$ Significant $(p<0.05)$

As BTM children get older, the morbidity prevents them from being more productive and a sense of inferiority might develop and lower their emotional domain scores [28]. Also, complications of the disease with its impact on physical morphology, treatment by repeated transfusion and iron chelation therapy with repeated invasive procedure and repeated hospital visits, all are emotionally demanding [27]. Establishment of supportive systems including some psychological consultation schedules in thalassemia clinics are mandatory.

Emotional functioning is one of the impaired domains of thalassemia patients and this study showed that thalassemia patients were lower emotionally functioning. Older children with thalassemia experienced fewer symptoms of depression, reflecting a process of adjustment and coping $[37,38]$ also suggests that thalassemia patients have their own coping strategies in dealing with their life. These patients seek the ability to satisfy some of their needs on their own and develop a sense of autonomy, but caregiver's refusal to let them perform these tasks owing to their illness may result in shame and doubt about their ability to handle problems [27]. Poverty can add more complex emotional burden to these patients as the parents

Table 4 Logistic regression analysis of factors predicting poor different QOL scores

\begin{tabular}{|c|c|c|c|}
\hline Variable & OR & $\mathrm{Cl}(95 \%)$ & $p$-value \\
\hline \multicolumn{4}{|l|}{ Physical } \\
\hline Age of transfusion (Older age) & 0.96 & $0.92-0.96$ & $0.03^{*}$ \\
\hline Hepatomegaly & 8.5 & $1.3-52.7$ & $0.02^{*}$ \\
\hline \multicolumn{4}{|l|}{ Emotional } \\
\hline House hold income (low) & 5.03 & $0.95-26.6$ & $0.043^{*}$ \\
\hline \multicolumn{4}{|l|}{ Social } \\
\hline Serum ferritin (high) & 1.1 & $1.001-1.1$ & $0.04^{*}$ \\
\hline \multicolumn{4}{|l|}{ Psychological } \\
\hline Age of transfusion (Older age) & 0.94 & $0.90-0.98$ & $0.01^{*}$ \\
\hline \multicolumn{4}{|l|}{ Total } \\
\hline Age of transfusion (Older age) & 0.94 & $0.90-0.98$ & $0.01^{*}$ \\
\hline
\end{tabular}

cannot provide a comfortable life suitable for the special needs of their children.

In the present study, the type of chelation therapy or the mode of administration had no impact on the different QoL domains. BTM patients have different causes to suffer. Coming from far areas to receive their scheduled transfusion or their planned medications, painful maneuvers either for blood sampling or transfusion, and the early and late complications of thalassemia. All these make the type of iron chelation therapy or the mode of administration to be secondary causes affecting the patient's QoL.

These results disagree with some previous studies, which reported that the type of iron chelation therapy compromises different aspects of QoL [39-41]. Other authors stated that, in addition to deferoxamine, deferiprone also appears to negatively impact QOL, probably because of its proved side effects [28].

Younger patients can show better QOL compared with older ones. Most of the beta thalassemia complications are cumulative, resulting from the continuous hemolytic process, the consequent of hemosiderosis, and the chance of acquiring transfusion-related infections. In BTM children, as they age, self-awareness increases with more cognition toward their illness status. Their ability to share and take the responsibility is challenged by the disease status. Inferiority sensation might develop which lower their emotional, social and psychological domain scores $[27,28]$.

\section{Limitation of the study}

This is the first study in Upper Egypt to assess the QOL in thalassemic children. Lack of cooperation of the patients' caregivers and their denying of many symptoms were the main challenge in this study. Refusal to participate in the study due to traditional thoughts limits the number of patients enrolled in this study.

\section{Conclusions}

In view of our findings, we conclude that quality of life and functioning is affected, thereby showing a need for better care in Egypt. Furthermore, Blood scarcity and transfusion delay may be augmenting the lower quality of life. This necessitates a more integrated planning for health services in Egypt.

\section{Abbreviations}

BTM: B-thalassemia major; HRQoL: Health-related quality of life; QoL: Quality of life; WHO: World health organization

\section{Acknowledgments}

To El Minya regional blood bank officials specifically Dr. Ahmed Abo El Kasem for his great cooperation with the research team.

Funding

Personally funded by the authors. 


\section{Availability of data and materials}

Available.

\section{Authors' contributions}

All authors are equally contributed. All authors read and approved the final manuscript.

\section{Authors' information}

Available.

\section{Ethics approval and consent to participate}

The study was conducted According to the declarations of Helsinki and approved from the faculty of medicine scientific committee.

Written consents were obtained from patients' caregivers.

\section{Consent for publication}

Available.

\section{Competing interests}

The authors declare that they have no competing interests.

\section{Publisher's Note}

Springer Nature remains neutral with regard to jurisdictional claims in published maps and institutional affiliations.

\section{Author details}

'Pediatric Department, Faculty of Medicine, Minia University, El Minya 61511, Egypt. ${ }^{2}$ Public health, Faculty of Medicine, Minia University, Minia 61511, Egypt.

Received: 18 February 2017 Accepted: 5 April 2018

Published online: 10 April 2018

\section{References}

1. Weatherall DJ, Clegg JB. The thalassemia syndromes. 4th ed. Oxford, England: Blackwell Science Ltd, 2001.

2. Rund D, Rachmilewitz E. Beta-thalassemia. N Engl J Med. 2005;353:1135-46. Article|PubMed||SI|ChemPort

3. Cao A, Galanello R. Beta-thalassemia. Available at: http://www.geneclinics. org. Accessed 1 Dec 2005.

4. Olivieri N, Weatherall DJ. Clinical aspects of $\beta$-thalassemia. In: Steinberg MH, Forget BG, Higgs DR, Nagel RL, editors. Disorders of hemoglobin, genetics, pathophysiology, and clinical management. Cambridge, England: Cambridge University, 2001;277-341.

5. Voskaridou E, Anagnostopoulos A, Konstantopoulos K, et al. Zoledronic acid for the treatment of osteoporosis in patients with beta-thalassemia: results from a single-center, randomized, placebo-controlled trial. Haematologica. 2006:91:1193-202.

6. Voskaridou E, Terpos E. New insights into the pathophysiology and management of osteoporosis in patients with beta thalassemia. $\mathrm{Br} J$ Haematol. 2004;127:127-39. Article|PubMed|ChemPort

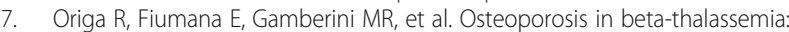
clinical and genetic aspects. Ann N Y Acad Sci. 2005;1054:451-6.

8. El Beshlawy A, Mokhtar G, Abd El Ghafar E, Abd El Dayem S, El-Sayed M, Aly A, Farok M. Assessment of puberty in relation to L-carnitine and hormonal replacement therapy in $\beta$-thalassemia patients. Tropical. Pediatrics. 2008; 54(6):375-81.

9. Atkin K, Ahmad W. Living a "normal life": young people coping with thalassemia major or sickle cell disorder. Soc Sci Med. 2001:53:615-26.

10. Caocci G, Efficace F, Ciotti F, Roncarolo MG, Vacca A, Piras E, Littera R, Markous RS, Collins GS, Ciceri F, Mandelli F, Marktel S, La Nasa G. Healthrelated quality of life in middle eastern children with beta-thalassemia. BMC Blood Disord. 2012;12:6.

11. Bowling A. Current state of the art in quality of life measurement. In: Carr AJ, Higginson IJ, Robinson P, editors. Quality of life. London: BMJ Books; 2003.

12. Varni JW, Burwinkle TM, Katz ER, Meeske K, Dickinson P. The PedsQLin pediatric cancer: reliability and validity of the pediatric quality of life inventory generic core scales, multidimensional fatigue scale, and cancer module. Cancer. 2002;94(7):2090-106.

13. Varni JW, Burwinkle TM, Seid M. The PedsQL 4.0 as a school population measure: feasibility, reliability, and validity. Qual Life Res. 2006;15:203-15.
14. Tefler P, Constantinidou G, Andreou P, Christou S, Modell B, Angastiniotis M. Quality of life in Thalassaemia. Annals of the New York Academy of Science. 2005;1054:273-82. https://doi.org/10.1196/annals.1345.035.

15. Pakbaz Z, Treadwell M, Yamashita R, Quirolo K, Foote D, Quill L, Singer T, Vichinsky EP. Quality of life in patients with Thalassaemia intermedia compared to Thalassaemia major. New York Academy of Sciences. 2005: 1054:457-61. https://doi.org/10.1196/annals.1345.059.

16. Guidelines for the management of non-transfusion dependent thalassemia (NTDT). Thalassaemia International Federation. 2013. Website: http://www.thalassaemia.org.cy.

17. Centers for Disease Control and Prevention. 2000. National Center for Health Statistics.

18. The PedsQL Measurement Model for the Pediatric Quality of Life Inventory. 2009. [http://www.pedsql.org/about_pedsql.htm].

19. Baghianimoghadam MH, Sharifirad G, Rahaei Z, Baghianimoghadam B, Heshmati $H$. Health-related quality of life in children with thalassemia assessed on the basis of SF-20 questionnaire in Yazd, Iran: a case-control study. Cent Eur J Public Health. 2011;19:165-9

20. Ismail A, Campbell MJ, Ibrahim HM, Jones GL. Health-related quality of life in Malaysian children with thalassemia. Health Qual Life Outcomes. 2006:4:39.

21. Cheuk DK, Mok AS, Lee AC, Chiang AK, Ha SY, Lau YL, Chan GC. Quality of life in patients with transfusion-dependent thalassemia after hematopoietic SCT. Bone Marrow Transplant. 2008;42:319-27.

22. Musallam KM, Khoury B, Abi-Habib R, Bazzi L, Succar J, Halawi R, et al. the health-related quality of life in adults with transfusion-independent thalassemia intermedia compared to regularly transfused thalassemia major: new insights. Eur J Haematol. 2011;87:73-9.

23. Safizadeh H, Farahmandinia Z, Nejad SS, Pourdamghan N, Araste M. Quality of life in patients with thalassemia major and intermedia in Kerman-Iran (I.R.). Mediterr J Hematol Infect Dis. 2012;4(1):e2012058.

24. Haghpanah S, Nasirabadi S, Ghaffarpasand F, Karami R, Mahmoodi M, Parand S, Karimi M. Sao Paulo Med J. 2013;131(3):166-72.

25. Nejad SS, Pourdamghan N, Araste M. Quality of life in patients with thalassemia major and intermedia in Kerman-Iran (I.R.). Mediterr J Hematol Infect Dis. 2012:4(1):e2012058.

26. Ansari SH, Baghersalimi A, Azarkeivan A, Nojomi M, Hassanzadeh Rad A. Quality of life in patients with thalassemia major. Iran J Ped Hematol Oncol. 2014;4(2):57-63.

27. El Dakhakhny AM, Hesham MA, Mohamed SE, Mohammad FN. Quality of life of school age thalassemic children at Zagazig City. J Am Sci. 2011;7:186-97.

28. Thavorncharoensap M, Torcharus K, Nuchprayoon I, Riewpaiboon A Indaratna K, Ubol BO. Factors affecting health-related quality of life in Thai children with thalassemia. BMC Blood Disord. 2010;10:1.

29. Gharaibeh HF, Gharaibeh MK. Factors influencing health-related quality of life of thalassaemic Jordanian children. Child Care Health Dev. 2012; 38:211-8.

30. Saeed N. My life. United Kingdom Thalassemia Society Matters. 2004;99:10.

31. Cantaan D, Ratip S, Kaptan S, Cosan R. Psychological burden of beta thalassemia major in Antalya, South Turkey. Soc Sci Med. 2003;56:815-9.

32. Anionwu E, Atkin K. The politics of sickle cell and Thalassaemia. Buckingham: Open University Press; 2001.

33. Naderi M, Hormozi MR, Ashrafi M, Emamdadi A. Evaluation of mental health and related factors among patients with beta thalassemia major in south east of Iran. Iran j psychiatry. 2012;7(1):47-51.

34. Yahia S, El-Hadidy MA, El-Gilany AH, Anwar R, Darwish A, Mansour AK. Predictors of anxiety and depression in Egyptian thalassemic patients: a single center study. Int J Hematol. 2013;97(5):604-9.

35. Aydinok Y, Eremis S, Bukusoglu N, Yilmaz D, Solak U. Psychosocial implications of Thalassaemia major. Paediatr Int. 2005:47(1):84.

36. Goldbeck L, Baving A, Kohne E. Psychosocial aspects of beta thalassemia: distress, coping and adherence. Klinik Padiatrik. 2000;212(5):254-9.

37. Mikelli A, Tsiantis J. Brief report: depressive symptoms and quality of life in adolescents with b-thalassaemia. J Adolesc. 2004:27:213-6.

38. Coping in children with hemophilia and thalassemia: A cross-national study. 2010. [http://eprints.ecs.soton.ac.uk]

39. McLeod C, Fleeman N, Kirkham J, Bagust A, Boland A, Chu P, et al. Deferasirox for the treatment of iron overload associated with regular blood transfusions (transfusional haemosiderosis) in patients suffering with chronic anemia: a systematic review and economic evaluation. Health Technol Assess (Rockv). 2009;13:iii-v. 
40. Elalfy MS, Massoud W, Elsherif NH, Labib JH, Elalfy OM, Elaasar S, et al. A new tool for the assessment of satisfaction with iron chelation therapy (ICT-sat) for patients with b-thalassemia major. Pediatr Blood Cancer. 2012;58:910-5.

41. Ho PJ, Tay L, Lindeman R, Catley L, Bowden DK. Australian guidelines for the assessment of iron overload and iron chelation in transfusiondependent thalassemia major, sickle cell disease, and other congenital anemias. Intern Med J. 2011;41:516-24.

Ready to submit your research? Choose BMC and benefit from:

- fast, convenient online submission

- thorough peer review by experienced researchers in your field

- rapid publication on acceptance

- support for research data, including large and complex data types

- gold Open Access which fosters wider collaboration and increased citations

- maximum visibility for your research: over $100 \mathrm{M}$ website views per year 